Research Article

\title{
Shear Characteristics and Strength Criterion of Frozen Joints under Different Opening Degrees
}

\author{
Shiwei Shen $\left(D,{ }^{1}\right.$ Lin Gan, ${ }^{1}$ Chang Liu $\left(D,{ }^{1,2}\right.$ and Shulin Dai ${ }^{1}$ \\ ${ }^{1}$ College of Construction Engineering, Jilin University, Changchun, Jilin 130026, China \\ ${ }^{2}$ College of Art and Design, Jilin Jianzhu University, Changchun, Jilin 130118, China
}

Correspondence should be addressed to Chang Liu; liuchang@jlju.edu.cn

Received 13 November 2020; Revised 8 December 2020; Accepted 28 December 2020; Published 30 January 2021

Academic Editor: Zhi Cheng Tang

Copyright (c) 2021 Shiwei Shen et al. This is an open access article distributed under the Creative Commons Attribution License, which permits unrestricted use, distribution, and reproduction in any medium, provided the original work is properly cited.

Samples of rock coupling joints were collected from the Jiangluling Tunnel of the G214 line in Qinghai province. Models with surface topographies similar to these joints were manually created. Freezing shear tests under different normal stress conditions were conducted to study the shear mechanical properties of these models. On this basis, the integral form of the peak shear strength criterion of frozen joints was proposed. Results show that the shear process of the ice layer can be divided into four stages, namely, initial deformation, continuously increasing shear stress, ice shearing, and residual shear. During the continuously increasing shear stress stage, the stress-strain curve is concave, and elastic deformation is not evident. Furthermore, the increase rate of shear stress generally rises as normal stress intensifies. In the ice shearing stage, shear stress does not decrease instantaneously, but plastic deformation is now detectable. When the opening degree is greater than the undulation difference of the joint surface under the action of all levels of normal stress, the shear stress in the ice sharply increases and drops due to local failure and reicing. Then, evident difference between the shear processes under freezing and normal temperature conditions was then obtained. On this basis, the failure forms of joint surfaces, theory of ice adhesion strength under different opening degrees and morphologies, and the shear failure forms of frozen joints under different conditions were considered. The integral form of the peak shear strength criterion of frozen joints was proposed. These results can lay a theoretical foundation for the stability analysis of rock mass engineering in permafrost areas.

\section{Introduction}

China is the third largest permafrost area globally, accounting for about $70 \%$ of the total land area. Rock mass engineering in permafrost areas is bound to encounter rock mass freezing. The structural plane of rock mass is the weakest part, and it plays a decisive role in the stability of rock mass engineering. The shear mechanical characteristics of joints are the main influencing factor in the stability of the rock slope and foundation engineering. Therefore, the same influencing factor is crucial in the stability of the rock slope and foundation engineering in permafrost areas. Shear strength controls the sliding failure of joints. Therefore, research on shear mechanical characteristics and strength criteria of frozen joints has important theoretical and practical significance for the stability of rock mass engineering in permafrost areas.
Over the past 40 years, scholars made important progress in this field. Barton [1] concluded that, under low normal stress condition (less than $40 \%$ of rock ultimate compressive strength), morphology is the main controlling factor of joint peak shear strength. On this basis, Grasselli [2] proposed that the peak shear strength of joints can be explained reasonably by using the $3 \mathrm{D}$ morphological parameters of joints. In addition, the contact state of joints is also an important factor affecting the peak shear strength of joints. In addition, various shear tests were performed on natural rock $[3,4]$ and cement mortar $[5,6]$; these tests revealed the variation of shear displacement, shear strength criterion, and dilatancy angle of joint surfaces under different 3D morphologies and acceptance conditions.

In the research of shear mechanical characteristics of frozen rock and soil, Yulin et al. [7], Jing et al. [8], and 
Anping et al. [9] took different properties of the soil as research objects and designed different test conditions to study the shear mechanical characteristics of frozen rock and soil under freezing and freeze-thaw cycles. Shunying et al. [10] took the sea ice of the Bohai Sea as the research object and conducted side-limited unilateral shear test under different loading speed, salinity, and temperature conditions; they analyzed the effects of these factors on the shear strength of the sea ice using experimental data and determined the functional relationships among brine volume, lateral stress, and shear strength. Qing et al. [11], Bo et al. [12], and Hongwei et al. [13] selected ice samples of different properties, analyzed the samples' internal structure, and conducted shear tests at different test temperatures and strain rates; they obtained the variation of shear strength with different strain rates and temperatures and the relationship between bubble content and shear strength.

In a study of the mechanical characteristics of rock joints under low temperature or freeze-thaw cycles, Tharp [14] analyzed the frost heave of cracks and reported the widthdepth ratio of cracks; moreover, the shape of the crack tip had greater influence on the frost heave of cracks than the mechanical characteristics of rocks on both sides. Friederike [15] established the correlation between normal and shear strains of the concrete rough joint surface as well as ice body and concrete interface by shear test after freezing the artificial joint. Davies et al. [16] used centrifugal model test to test the temperature rise of the rock slope structural plane under freezing conditions and obtained the displacement field in the slope body; on this basis, they analyzed the stability of the slope. Davies et al. [17] conducted shear strength test on the rough interface between ice and concrete and established the relationship among normal strain, shear strain, and shear stress. Martin and Rivard [18] studied the strength deterioration of concrete under freeze-thaw cycles via shear test by taking joints of a dam body as the research object. In China, Quansheng et al. [19] analyzed the influence of the angle between the frozen front and the fissure surface on the fissure frost heave. Caichu et al. [20] reported three kinds of situations in the fissures, namely, in situ frost heaving of fractured water, fracture water discharge (no frost heaving), and frost heaving of crack ice growth caused by water and heat transfer. However, the mechanical characteristics of rock joints under freezing conditions have not yet been investigated locally and abroad.

Previous studies on the mechanics of frozen joints primarily consider the frost heave characteristics of joints, and most research objects are artificial joints or the shear strength of the interface between ice and concrete. However, the peak shear strength criterion of natural rock joints, especially frozen joints, still requires further research. In the current study, freezing shear tests of rock coupling joints (upper and lower joints fully coincide) in the Jiangluling Tunnel of the G214 line in Qinghai province are conducted to reveal the mechanical characteristics of freezing shear of joints under different normal stress conditions and the difference between the mechanical characteristics of freezing shear of joints and of conventional joints. On this basis, the integral form of the peak shear strength criterion of freezing joints under different conditions is derived. The research results can provide theoretical basis for stability analysis of rock mass engineering in permafrost areas.

\section{Specimen Preparation and Test Method}

The shear tests of rock joints belong to destructive test. The failure of the original joint surface morphology is inevitable when applying shear stress. Thus, the original rock joints cannot be repeatedly used for another test. To ensure the consistency of the initial state of joint specimens in the same group, artificial specimens should be prepared on the basis of the original rock joints.

2.1. Preparation of Artificial Joint Specimens. On the basis of previous studies on the effect of structural plane size on shear strength, the difficulty of sampling and the direction of shearing are considered at the same time. Therefore, a rectangular structural surface with a size of $200 \times 100 \times 100 \mathrm{~mm}$ is selected. The original rock joint surface of the specimens is selected, and the upper and lower plates of each group of joints are numbered. After surface cleaning treatment, the lower plates of each group of joints are initially placed in a standard mold with the same size as the shear box (length $\times$ width $\times$ height $=200 \mathrm{~mm} \times 100 \mathrm{~mm}$ $\times 100 \mathrm{~mm}$ ). The inner parts of the mold are filled with cement mortar. In this manner, the joint surface is slightly higher than the mortar plane. After spraying vegetable oil on the surface of the specimen, the isolation film is set up. To bring them close together, the bubbles between the isolation film and the joint surface are removed.

In order to ensure the similarity between artificial joints and natural rock joints in terms of strength, the artificial joints are prepared using reverse control technology. The specific preparation process and parameters are as follows. The processed inner contour has the same shape as the original rock joint's outer contour. The outer contour has the same size as the shear box. The upper and lower parallel wooden modules are set on the original rock joint surface to form the area of artificial joints poured on the upper wall. In accordance with the design proportion, the raw materials of mortar are weighed and stirred evenly, and the mixture is poured into the mold. Ordinary Portland cement (42.5 R), standard sand, and water are selected. The mass ratio of water : cement: sand is $1: 2: 3$. Silica powder $(10 \% 920 \mathrm{U})$ and superplasticizer $(2 \%$ FDN-F 2) are added at the same time. To ensure that the artificial material is closely connected with the joint surface, plate vibrator and vibrating rod are used to vibrate evenly, and the bottom isolation film is not folded. After pouring, the upper surface is smoothed, leveling it with the mold. After the specimen is maintained in water, the whole mold is turned over, and the isolation film is removed after removing the mold. The artificial joint surface of the upper plate, which is completely consistent with the lower plate of the original rock joint surface, is created $[16,17]$.

The man-made joint surface of the upper plate is then placed in the standard mold by repeating the above steps. At the same time, the man-made joint surface of the lower plate, 
which is completely consistent with the previous surface, is prepared. The artificial joint specimens with the same composition and roughness are prepared by repeating the above steps.

2.2. 3D Scanning of the Joint Surface. TJXW-3D portable rock surface 3D topography instrument is used to scan 3D joints. The equipment photos are shown in Figure 1. The 3D morphology of each group of joints is shown in Figure 2.

The profiler uses an active triangulation method that combines stereo vision and binocular imaging methods. The measurement principle is through a digital grating projection device; a series of continuous grating stripes of different widths are projected on the surface of the object, which are affected by the surface shape to form deformed stripes, which are captured and recorded by the left and right cameras, and then calculated and compared by the left and right cameras. The results are matched to obtain the threedimensional coordinates of the points on the measured surface, and then the surface topography parameter calculation formula is used to obtain the topography parameters of the object surface.

As shown in Figure 2, the maximum height difference (fluctuation difference) of the four groups of joints is about $10 \mathrm{~mm}$, and the overall fluctuation difference is equal. However, the convexity and concavity of each group of joints are different. When subjected to horizontal shear, the convex part of the joint surface will prevent the production of horizontal displacement, which is the main part of its shear strength. In addition, when the joint surface is frozen with water, the part of the back shear direction is separated during the shear process, and the bond between the ice layer and the joint surface is also a component of shear strength.

2.3. Specimen Freezing. In this test, the rock coupling (complete occlusion of the upper and lower joints) joints of the Jiangluling Tunnel on the G214 line in Qinghai province are selected, and the joints are poured following the process described in the previous section. After 28 days of maintenance under standard conditions (temperature $20^{\circ} \mathrm{C}$ and relative humidity 90\%), the joints are frozen.

According to relevant regulations, the freezing time of the rock freeze-thaw cycle test is not less than 4 hours. However, because of the large joint area, the ice layer will be completely frozen after 12 hours during the test. At the same time, according to the on-site temperature survey of the Jiangluling Tunnel, the lowest temperature in this place is about $-35^{\circ} \mathrm{C}$. To ensure that the test environment is close to the site, the freezing temperature is chosen to be set at $-35^{\circ} \mathrm{C}$. In accordance with the test design plan, the upper and lower joint surfaces are reserved for a certain amount of opening and placed in the finishing box. Except for the joint area, the remaining void parts are filled with the high-density EPS foam gasket. Water in the finishing box is placed in a lowtemperature control box and then frozen at $12-35 \mathrm{~h}$. The schematic of freezing is shown in Figure 3. The photos before and after freezing are shown in Figure 4. After freezing, the area where the joint surface is located (the white area on the

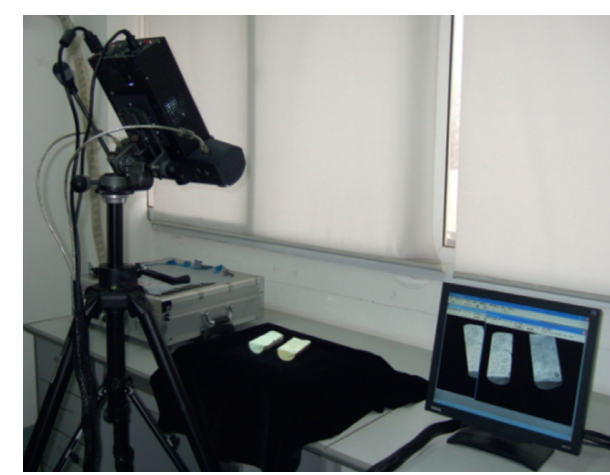

FIgURE 1: 3D scanner of the rock joint morphology.

right of Figure 3 ) is filled with ice. Its range is a rectangle surrounded by the maximum distance between the joint surface in the transverse and longitudinal directions.

2.4. Method and Process of Direct Shear Test. The shear test adopts the shear test machine of rock joints from the Key Laboratory of the Ministry of Geotechnical and Underground Engineering of Tongji University. The machine is composed of horizontal loading, vertical loading, and servo control systems. The photo of the test machine is shown in Figure 5.

In this study, the relative opening of the joint surface is the difference between the highest and lowest joint opening/ joint surface height. The height difference of each joint surface is between 10 and $10.5 \mathrm{~mm}$. Hence, the opening of frozen joints is designed to be 7,10 , and $13 \mathrm{~mm}$ (i.e., the relative opening is $0.7,1.0$, and 1.3 , respectively) to highlight the effect of joint fluctuation on its shear properties. The same rock joint surface is used for testing to ensure the consistency of joint surface roughness and fluctuation in the same group of shear tests. Prior to the shear test, the joint is reserved for design opening and placed in a low-temperature control box to be frozen with water. To obtain the freezing shear characteristics of joints under different normal stresses and avoid the failure of ice under normal pressure, the shear tests of joints under normal stresses of $0.5,1.0,1.5$, and 2.0 $\mathrm{MPa}$ are performed. The strength of the mortar prepared by the mixture ratio in the article can reach M7.5, and the maximum value of the normal stress applied in the test is only $2.0 \mathrm{MPa}$, which can completely ensure that the mortar has no damage during the experiment. Normal stress is applied to the design value in accordance with the load control mode, and the shear load is then applied in accordance with the deformation control mode.

During the test, a displacement sensor is installed at the four corners of the specimens, and the normal stress loading rate is set as $2 \mathrm{~mm} / \mathrm{min}$. The normal displacement and corresponding normal stress of the specimens during the loading process are read in real time. After adding the design load, the normal displacement sensor data are read every $5 \mathrm{~min}$. The normal load is considered stable when the difference between two adjacent normal displacements is less than $0.01 \mathrm{~mm}$. When the normal stress loading stabilizes, horizontal load is applied to the specimens, and shear tests 


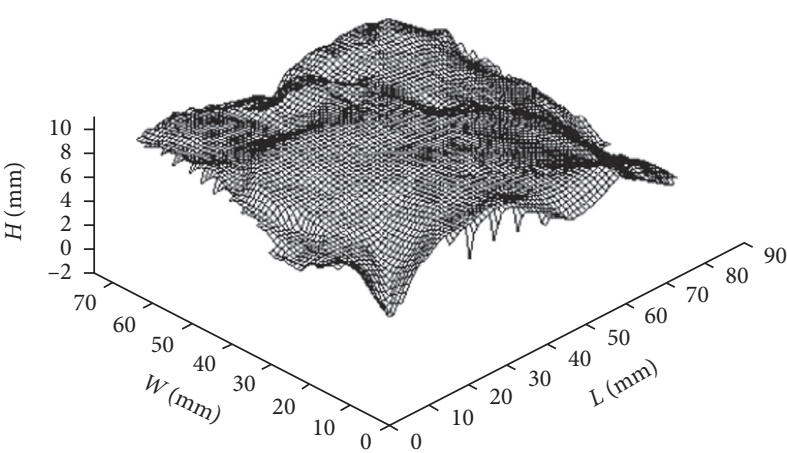

(a)

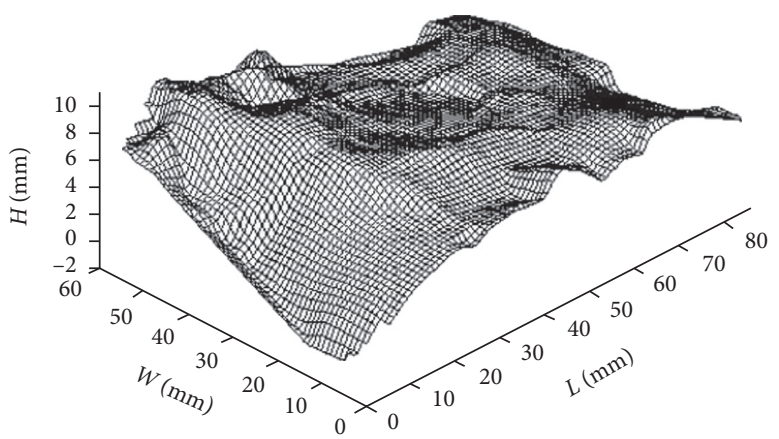

(c)

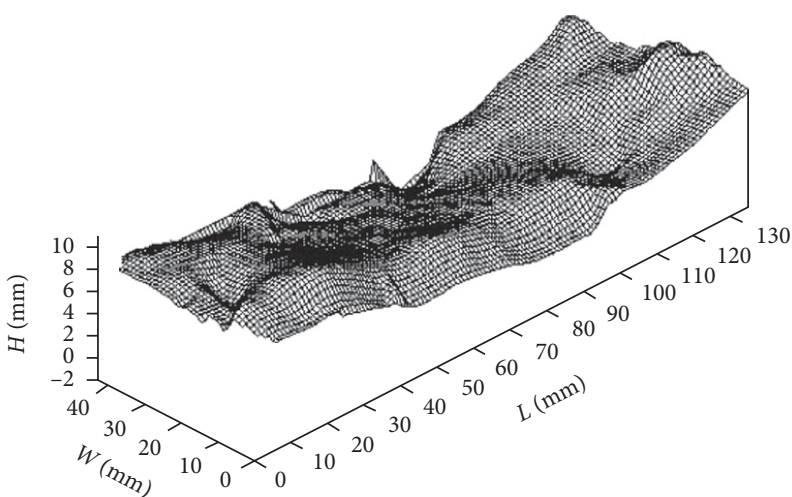

(b)

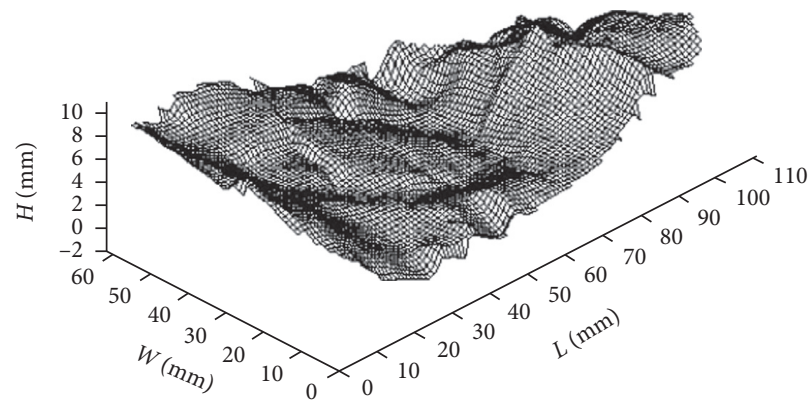

(d)

FIGURE 2: 3D topography of joint surfaces in each group. (a) Specimen 1. (b) Specimen 2. (c) Specimen 3. (d) Specimen 4.
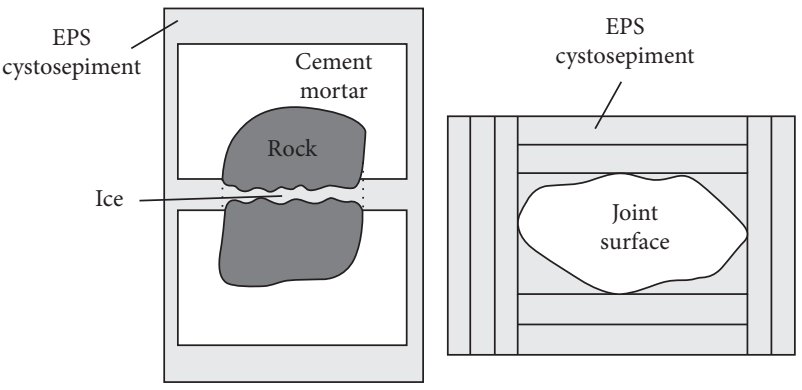

Figure 3: Schematic of freezing.

are conducted at a loading rate of $2 \mathrm{~mm} / \mathrm{min}$. Four horizontal displacement sensors are installed in the shear direction to read the shear displacement in the shear process in real time. The shear stress values of the specimens in the shear process under various test conditions are read by the shear stress sensors. Figure 6 shows the sensor installation photo.

\section{Analysis of Test Results}

To study the influence of different normal stresses on the shear characteristics of frozen joints, four groups of joints are subjected to $0.5,1.0,1.5$, and $2.0 \mathrm{MPa}$ normal stresses.

3.1. Analysis of Freezing Shear Behavior of Joints with $7 \mathrm{~mm}$ Opening Degree. The shear stress-shear displacement curves of each group of specimens at $7 \mathrm{~mm}$ opening degree are shown in Figure 7.

As shown in Figure 7, the shear stress-shear displacement curve of frozen joints can be divided into the following four stages when the joint opening degree is $7 \mathrm{~mm}$ : (1) initial deformation stage: at this stage, the shear stress increases instantaneously (usually, 0.5-1.0 MPa). Also, no evident shear displacement occurs in the ice layer (usually, the shear displacement is less than $1 \mathrm{~mm})$. However, as shown in Figures 7(c) and 7(d) schematics, a small abrupt change in shear stress occurs because water forms bubbles and voids in ice crystals during the freezing process, which are compacted under horizontal loads. At the same time, ice crystals around bubbles produce local rupture phenomenon, which leads to changes in shear stress. (2) Continuously increasing shear stress stage: continuous shear displacement occurs, and shear stress increases at this stage. The shear stress-shear displacement curve shows a concave form. Afterwards, ice shows a quasi-elastic property. With the increase in normal stress, the increase rate of shear stress increases gradually. (3) Ice shearing stage: when shear stress reaches the ultimate strength of ice, the shear stressshear displacement curve begins to show a distinct convex form, and the ice begins plastic deformation. After the ultimate shear stress, the shear stress begins to decrease. (4) Residual shear stage: when the shear displacement reaches $15-20 \mathrm{~mm}$, shear stress decreases with the increase in the shear displacement. However, the shear stress does not show the catastrophic property because the ice layer does not lose its strength completely. 


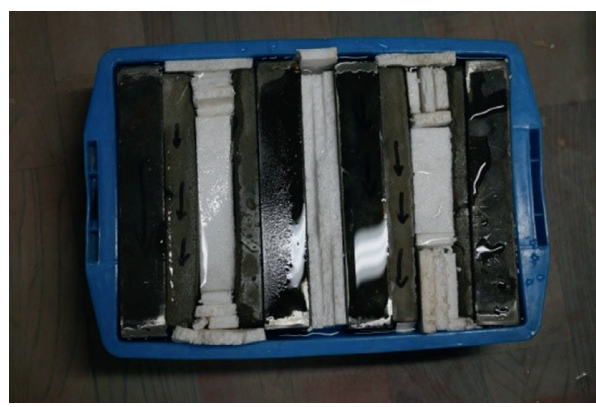

(a)

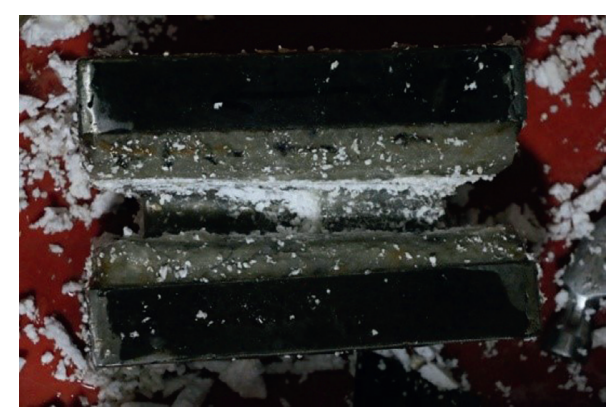

(b)

FIgURE 4: Photographs of the specimen before and after freezing.

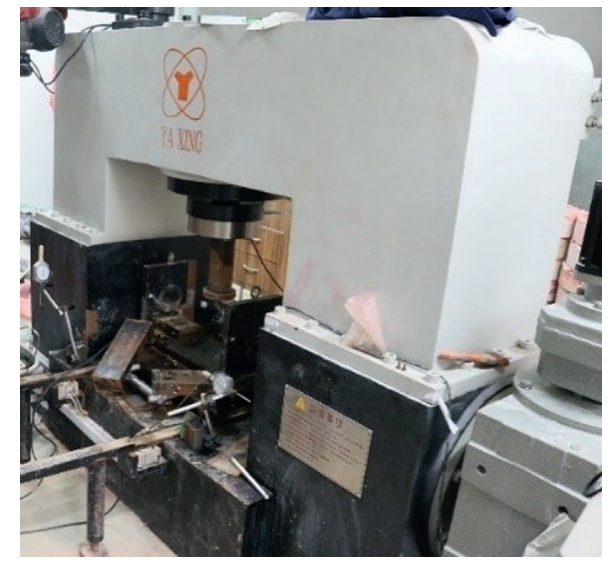

(a)

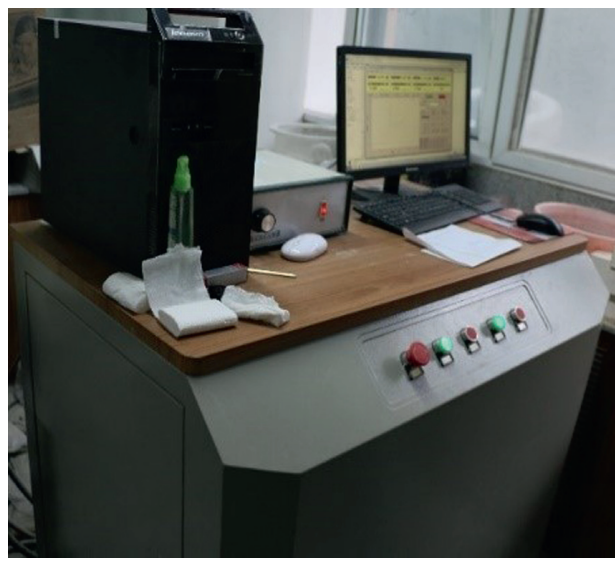

(b)

Figure 5: Shear test equipment. (a) Main engine. (b) Operator.

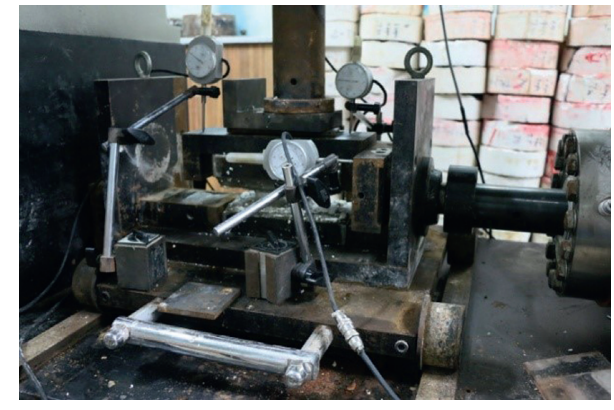

Figure 6: Displacement sensor installation photo.

Combined with the above phenomena, when the joint opening degree is less than the fluctuation of the rock joint surface (relative opening degree is less than 1), under normal stress, the ice will first produce 1-2 mm compressive deformation, which further reduces the relative opening degree. Therefore, the horizontal displacement of the ice layer is mainly caused by the slope-climbing effect along the rock joint surface. Producing brittle fracture is difficult. During ice layer shear-climbing, the protruding part of the original rock joint surface is closely occluded. Hence, the shear stress resistance ability is strong. The shear failure of the ice layer occurs at this time, which is similar to creep failure. No evident shear fracture surface exists in the ice layer, but a flexible failure occurs when the bond strength between the ice layer and rock joints decreases gradually with the increase in shear displacement. After the shear test, the ice layer and the rock joint surface are not separated. However, the increase in shear displacement causes an evident dislocation phenomenon, and a certain bond strength between them is formed.

3.2. Analysis of Freezing Shear Behavior of Joints with $10 \mathrm{~mm}$ Opening Degree. The shear stress-shear displacement curves of each group of specimens at $10 \mathrm{~mm}$ opening degree are shown in Figure 8.

As shown in Figure 8, when the opening degree is $10 \mathrm{~mm}$, the shear stress-shear displacement curve of frozen joints is generally similar to that of $7 \mathrm{~mm}$ opening degree. This curve can be divided into four stages: (1) initial deformation stage: the shear stress increases sharply in the initial stage of shear action because of the strength of the ice layer itself and the bonding effect between the ice layer and the rock joint interface. This phenomenon is shown by the instantaneous increase in the shear stress when the 

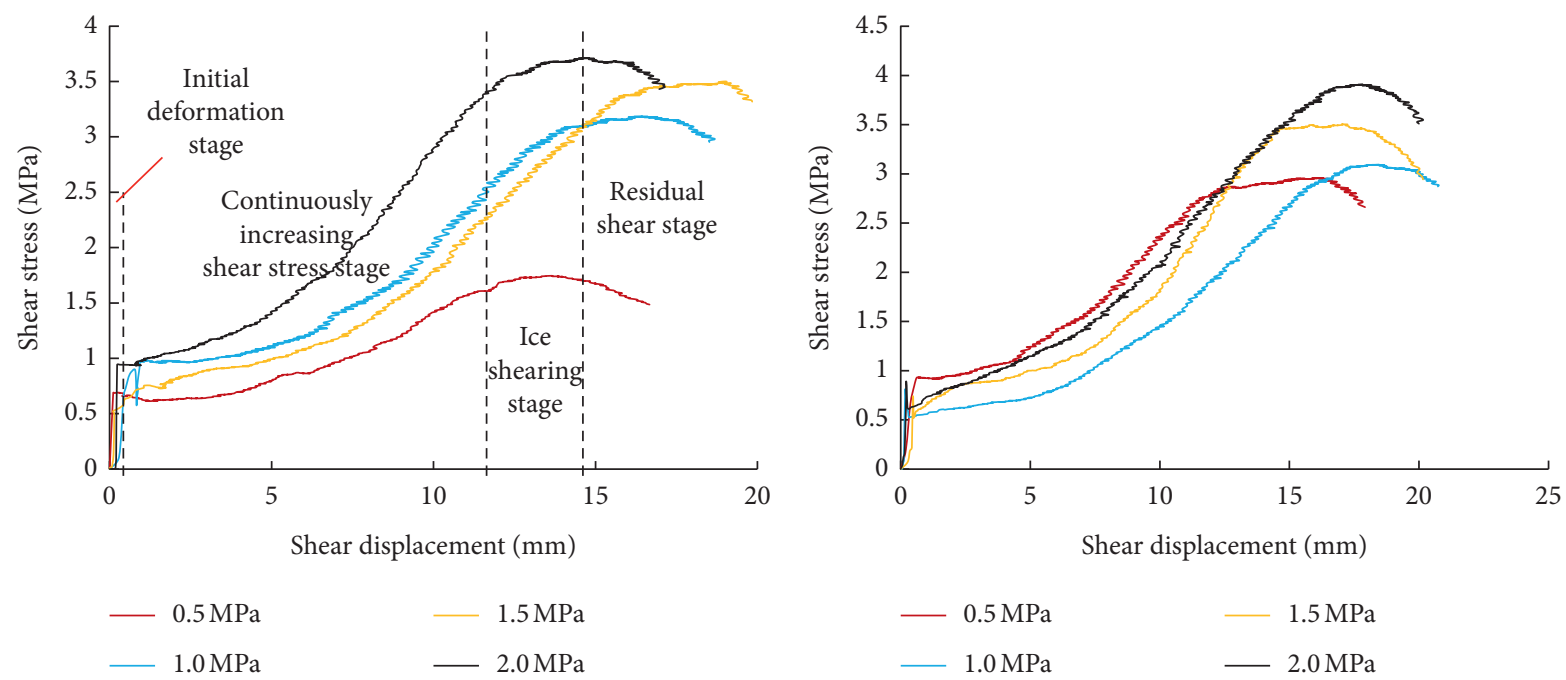

(b)
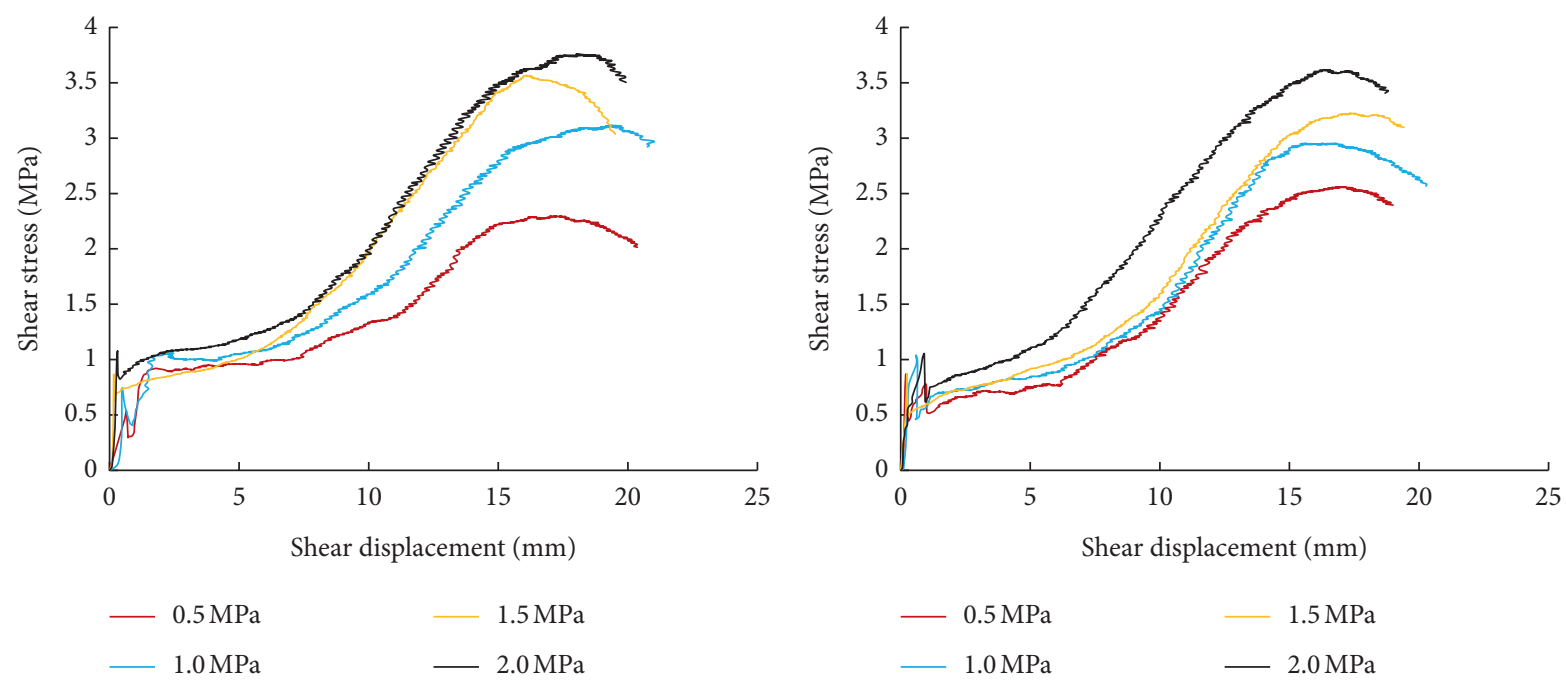

(d)

(c)

FiguRE 7: Shear stress-shear displacement curves of different normal stress joints with $7 \mathrm{~mm}$ opening degree. (a) Specimen $1 \#$. (b) Specimen 2\#. (c) Specimen 3\#. (d) Specimen 4\#.

horizontal displacement of the shear plane is less than $1 \mathrm{~mm}$ (about $0.5-1 \mathrm{MPa}$ ). (2) Continuously increasing shear stress stage: at this stage, the characteristics of the shear stressshear displacement curve are similar to those of $7 \mathrm{~mm}$ openness. Generally, this curve shows concave characteristics. The rate of increase in shear stress rises as normal stress intensifies. However, the difference between the two is that the shear stress of the three specimens rapidly increases and drops at this stage. This difference is reflected under normal stress at all levels. The reason for this difference is the certain thickness of the ice layer at this time (when normal stress is applied, the ice will produce normal displacement, and its relative opening degree will decrease to $0.8-0.9$ ). Therefore, during the shear process, no contact is made between rock joint planes, and the ice layer has certain brittle and destructive properties. When the ice layer is subjected to normal stress, the local failure occurs during shear, and the shear stress increases and decreases sharply. At the same time, secondary compaction and cohesive force increase after ice breaking under normal stress. Moreover, the heat generated during the shear process makes the ice melt locally, and the ice melt rapidly contacts with the unmelted ice, resulting in reicing. Therefore, the increasing trend of shear stress is the same as that before the sharp increase in shear stress. (3) Ice shearing stage: when the shear displacement increases to about $15 \mathrm{~mm}$, the ice begins to produce plastic deformation, and the shear stress-shear displacement curve is transformed into a distinct concave feature. However, due to the slow loading rate of shear stress $(2 \mathrm{~mm} / \mathrm{min})$, brittle shear failure does not occur in the ice layer. (4) Residual shear stage: when the ice layer is sheared, the shear stress decreases gradually, but the shear stress does not show steep drop due to the cementation between the ice layer and the rock joints. However, from the residual shear stage curve 

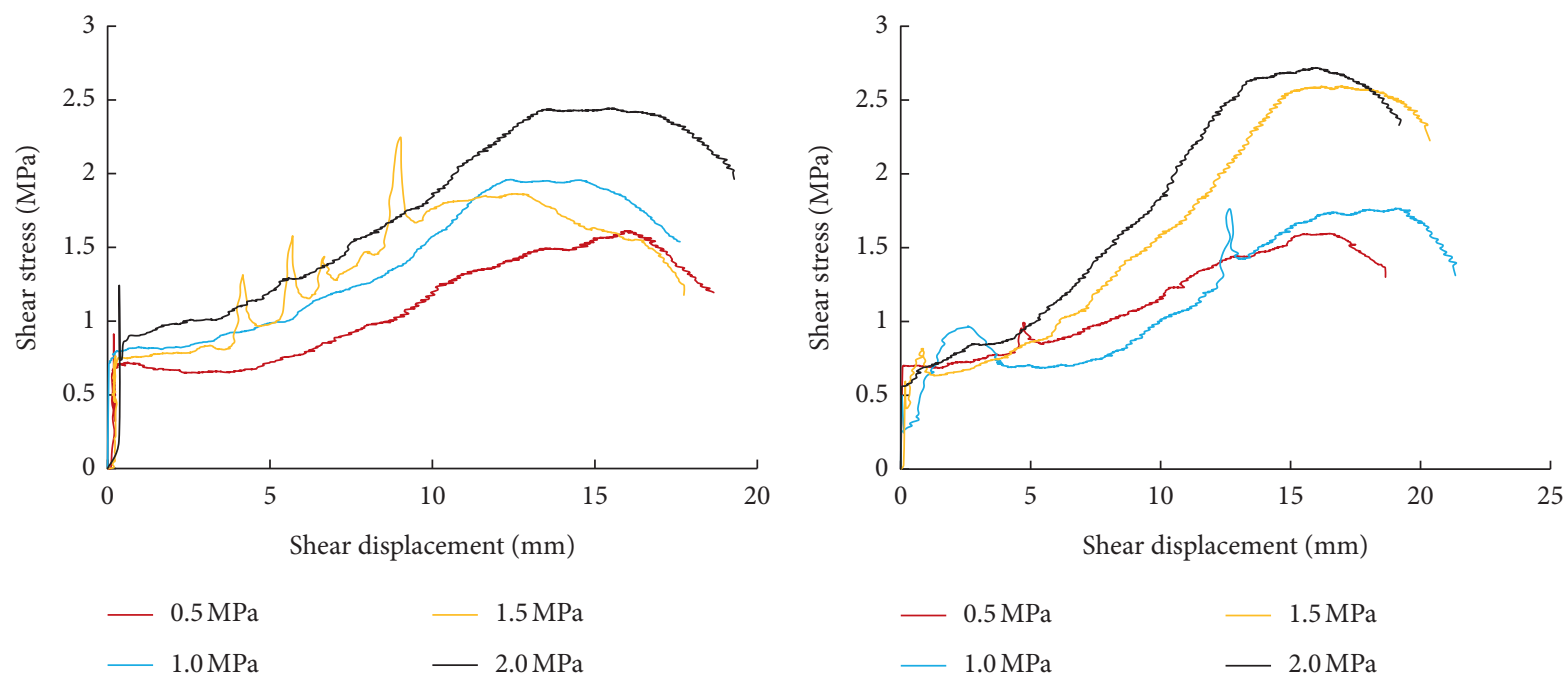

(a)

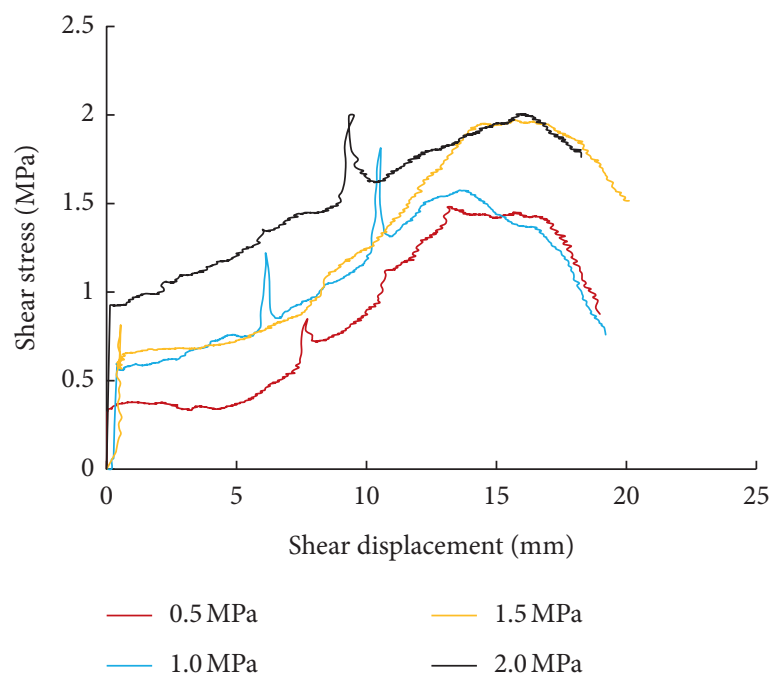

(c)

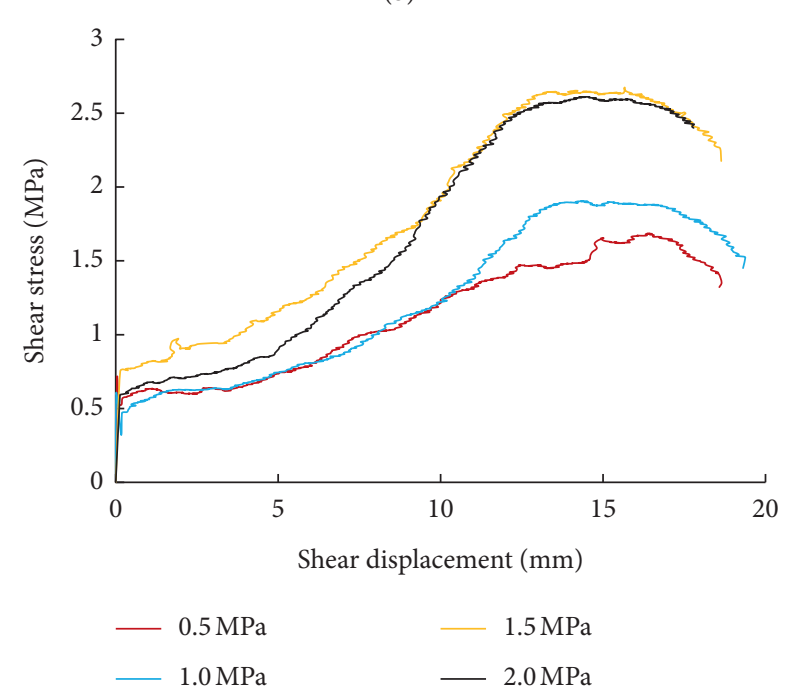

(d)

FIGURE 8: Shear stress-shear displacement curves of different normal stress joints with $10 \mathrm{~mm}$ opening degree. (a) Specimen 1\#. (b) Specimen 2\#. (c) Specimen 3\#. (d) Specimen 4\#.

analysis under different normal stress conditions, the shear stress reduction rate increases with the increase in normal stress.

In accordance with the shear test results under the condition of $10 \mathrm{~mm}$ opening degree (relative opening: 1.0), the ice initially produces a certain normal displacement under various normal stresses. Therefore, the relative opening degree of the ice is $0.8-0.9$ in the shear process. Under this condition, except for areas with a large fluctuation of rock joint surfaces, joint surfaces do not collide with one another. At this time, the ice layer behaves between "pure shear-climbing." In comparison with the condition with $7 \mathrm{~mm}$ opening degree, the climbing effect is evidently weakened, and the ability of resisting shear stress is reduced. Therefore, when the opening degree is $10 \mathrm{~mm}$, the increasing speed of shear stress in the continuously increasing shear stress stage is less than that of the $7 \mathrm{~mm}$ opening degree, and the peak shear stress is smaller than that of the $7 \mathrm{~mm}$ opening degree under similar conditions.

\subsection{Analysis of Freezing Shear Behavior of Joints with $13 \mathrm{~mm}$} Opening Degree. The shear stress-shear displacement curves of each group of specimens under the condition of $13 \mathrm{~mm}$ opening degree are shown in Figure 9.

As shown in Figure 9, the shear stress-shear displacement relationship curve under the condition of an opening degree of $13 \mathrm{~mm}$ is evidently different from that under opening degrees 7 and $10 \mathrm{~mm}$. The absolute value of normal displacement has no significant change (still 1-2 mm) compared with the opening degree conditions of 7 and $10 \mathrm{~mm}$ under various normal stresses. However, the relative opening degree is greater than 1 . Therefore, during the shear process, the characteristics of each stage are as follows: (1) 

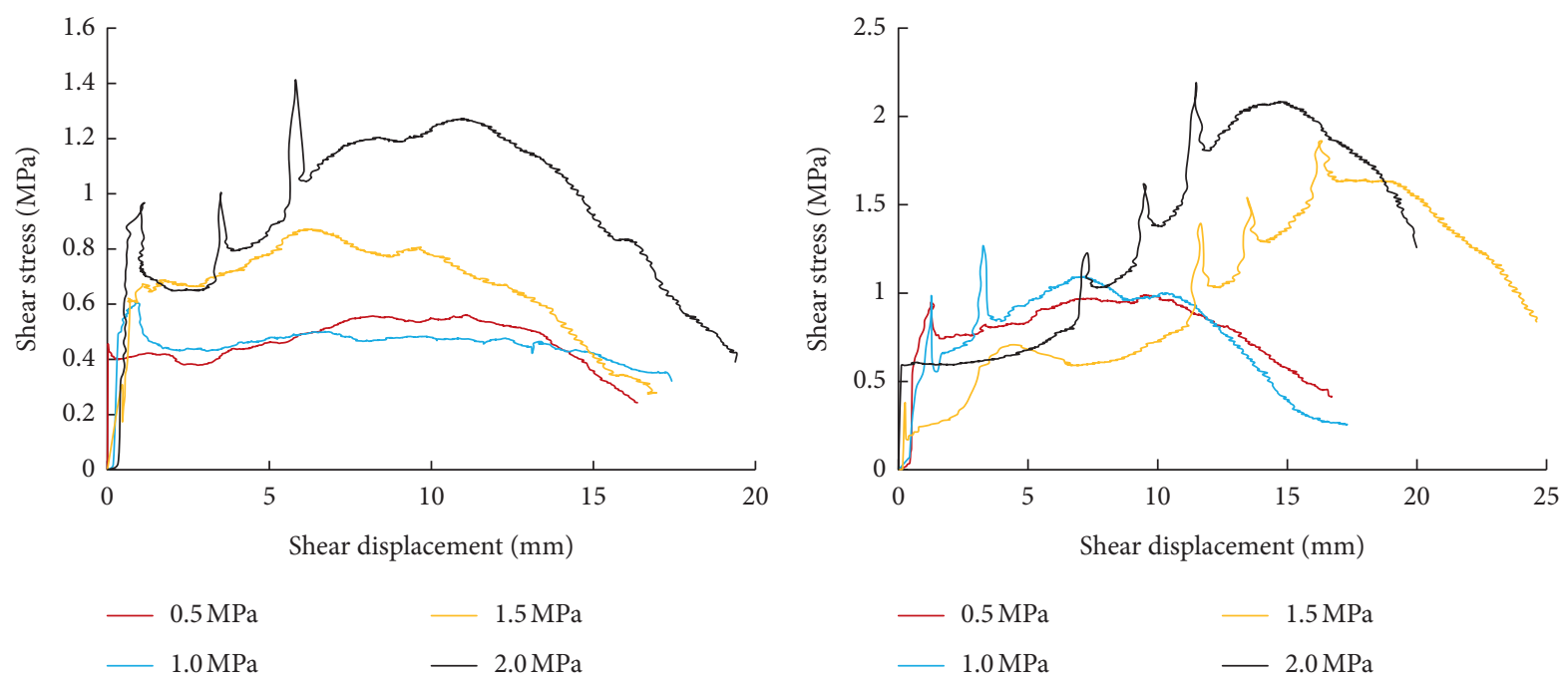

(a)
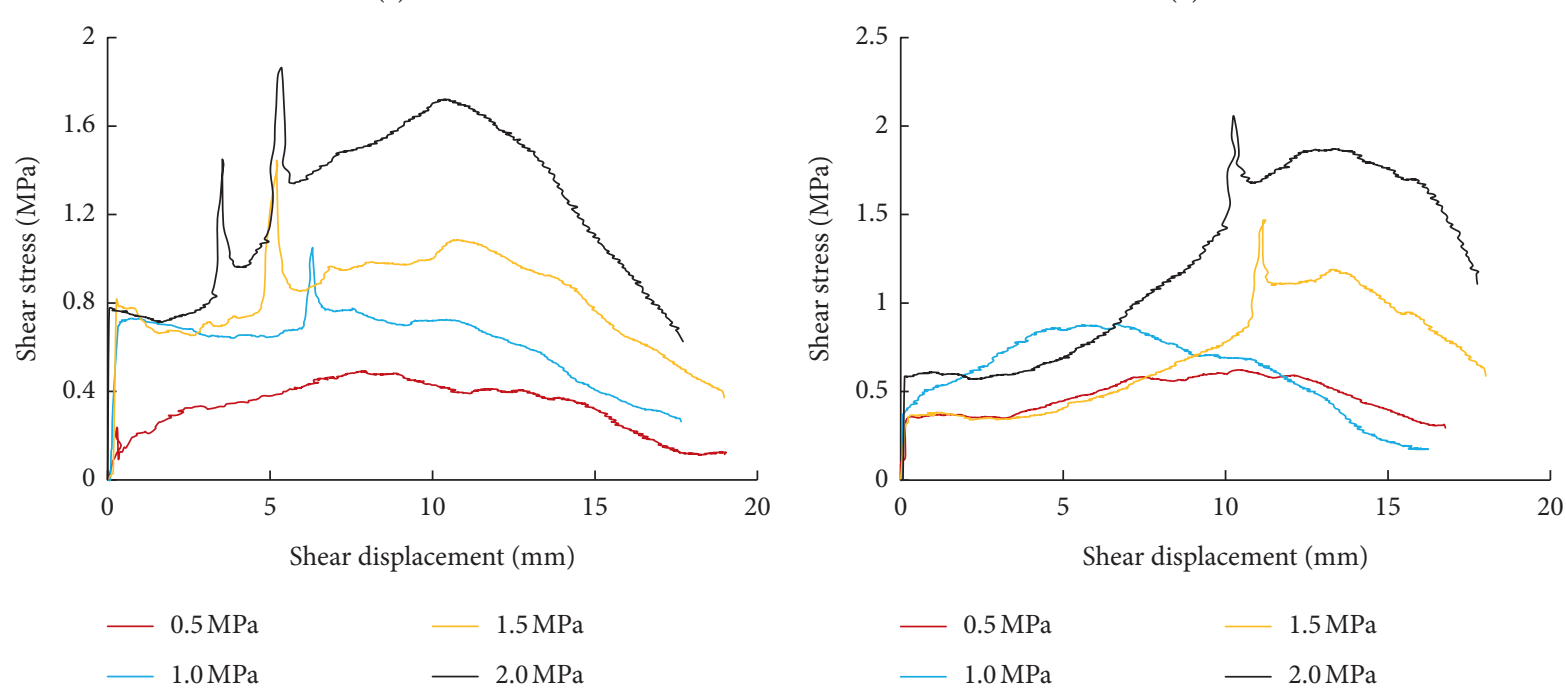

(d)

Figure 9: Shear stress-shear displacement curves of different normal stress joints with an opening degree of $13 \mathrm{~mm}$. (a) Specimen $1 \#$. (b) Specimen 2\#. (c) Specimen 3\#. (d) Specimen 4\#.

initial deformation stage: the increase in shear stress in this stage is only $0.4-0.8 \mathrm{MPa}$. Thus, for the case of relative opening degree greater than 1 , the compression effect of normal stress on the ice layer is not evident, and shear displacement can be produced under small shear stress. (2) Continuously increasing shear stress stage: the shear stress rapidly increases and drops at almost all levels of normal stress, and the increase is more evident than that under the condition of $10 \mathrm{~mm}$. When the relative opening degree is greater than 1, bubbles and voids in the ice layer are not fully compacted, and local damage easily occurs at this stage, thereby resulting in a sudden increase in shear stress. At the same time, the ice melts locally by absorbing shear friction heat and soon contacts with the surrounding ice body, thereby prompting reicing and restoring the strength of the ice. As the ice thickness increases, bubbles and voids, as well as local damage, increase. In other words, the greater the normal stress, the more evident the characteristics. When normal stress is large (i.e., 1.5 and $2.0 \mathrm{MPa}$ ), the shear stress increases sharply more than the maximum value of the subsequent increase. (3) Ice shear stage: the difference between this stage and the previous stage is significant, and the relative opening degree is greater than 1 . When the normal stress is small (i.e., 0.5 and 1.0 MPa), the failure mode of the ice layer is similar to that of the case where the relative opening degree is less than 1. Plastic deformation occurs in the ice layer, and this phenomenon increases the ultimate shear stress slowly. When the normal stress is large (i.e., 1.5 and $2.0 \mathrm{MPa}$ ), the shear stress increases sharply at a small shear displacement $(5-10 \mathrm{~mm})$. It then returns to normal rapidly and continues to increase. Meanwhile, the shear stress increases sharply than the subsequent maximum shear stress. When the relative opening degree is greater than 1 and the bubbles and voids in the ice layer are not fully compacted, the local cracks penetrate during the shear process, thereby forming a failure surface that causes a 
sudden increase in shear stress. The reicing caused by the contact of melted water formed by shear friction exothermic with the surrounding ice body restores its strength to a certain extent. However, in the subsequent shear process, the extreme shear stress of the recondensed ice layer is less than the previous steep increase stress due to the lower strength of the recondensed ice layer. (4) Residual shear stage: at this stage, the characteristics of the shear stress-shear displacement curve with relative opening degree greater than 1 are evidently different from those of other cases. The shear stress reduction rate increases evidently with the increase in normal stress, and the residual strength of the ice layer tends to be constant, which is similar to the residual strength of pure ice.

In accordance with the comprehensive analysis of the $13 \mathrm{~mm}$ open degree test, when the relative opening degree is greater than 1, bubbles and voids will be compressed under the normal stress at first, and slight damage will occur inside the ice crystal at the same time. These phenomena result in the reduction of ultimate shear strength under the normal stress at all levels due to the large thickness of the ice layer. During the shear process, the ice shows multiple local failure phenomena when the shear stress is applied and the normal stress is large (i.e., 1.5 and $2.0 \mathrm{MPa}$ ). These phenomena result in the sudden increase and decrease in the shear stress, accompanied by evident brittle failure phenomena. At the same time, the ultimate shear stress is due to the penetration of the ice fracture surface when the shear displacement is small. By contrast, when the opening degree is $13 \mathrm{~mm}$, the thickness of the ice layer after normal stress is still greater than the maximum fluctuation difference of the joint surface. Therefore, during the shear process, the joint surfaces of the rock upper and lower plates do not contact. The ice layer is always in pure shear process, and no climbing and gnawing occur. At this time, the failure process cuts along the weakest surface. Previous studies have shown that the bond strength at the ice-rock interface is much less than the shear strength of the ice itself. Hence, the shear stress growth rate and peak shear stress value at the opening degree of $13 \mathrm{~mm}$ are significantly lower than those at the opening degrees of 7 and $10 \mathrm{~mm}$.

\section{Peak Shear Strength Criterion of Frozen Joints}

On the basis of the analysis in the preceding section, the shear behavior of frozen joints is evidently different from that of conventional joints. Therefore, the shear strength criterion of conventional coupled joints is inapplicable to frozen joints. When the joint surface is frozen and filled with water, its peak shear strength is affected by the shear strength of the ice itself and the bond strength between the ice and the joint surface. Following this theory, the criterion of peak shear strength of frozen joints is established.

The coordinate system of the rock joint surface topography is established. The length direction of the joint surface is the $Y$-axis, the width direction is the $X$-axis, and the height direction is the $Z$-axis, as shown in Figure 10.

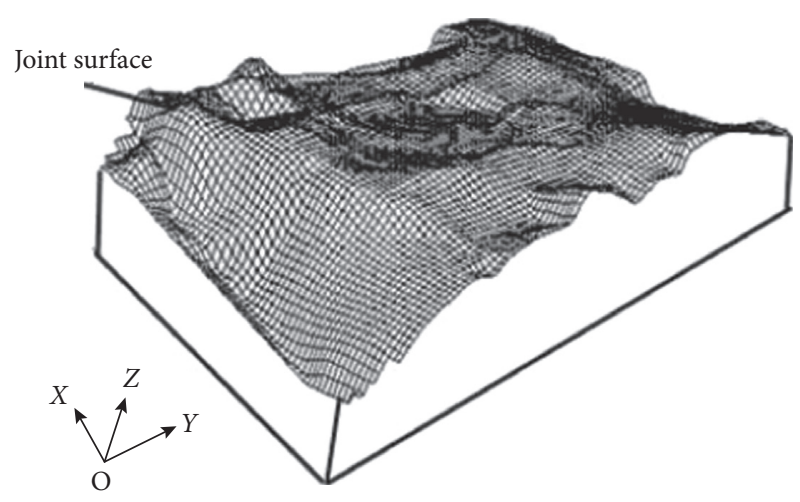

FIGURE 10: Schematic of the rock joint surface topography.

The joint surface is divided into several microelements. When it is sheared in the direction of the XOY plane, the microelements can be divided into two parts. If the angle between normal direction and shear direction is greater than 90 degrees, then the microelement body faces shear direction. It can also be regarded as an upward shear microelement body in the shear process. In the shear process on the joint surface, such microelements are characterized by the climbing effect. Wear or shear may occur in the process of ice shear displacement, which is the main aspect of resisting shear stress. If the angle between normal direction and shear direction in vitro is less than 90 degrees, then the microelement is separated during the shear process, and the strength of the microelement is the adhesion strength between the ice body and the joint surface. The shear schematic of the joint element is shown in Figure 11.

Following Mohr-Coulomb strength theory, in the shear process of the frozen joint surface, the shear stress of each element can be expressed as follows:

$$
\mathrm{d} \tau=c_{i} \mathrm{~d} l_{i} \cos \theta_{i}+\sigma_{n} \tan \left(\varphi_{i}+k\right),
$$

where $\mathrm{d} \tau$ is the shear strength (MPa) of the element length; $\mathrm{c}_{\mathrm{i}}$ is the cohesive force (MPa) of the ice or joint surface; $\mathrm{d} l_{i}$ is the infinitesimal length $(\mathrm{m}) ; \theta_{i}$ is the angle $\left(^{\circ}\right)$ between the microelement and the XOY plane; $\sigma_{n}$ is the normal stress $(\mathrm{MPa})$; and $\varphi_{i}$ is the internal friction angle $\left(^{\circ}\right)$ of the ice or joint surface. $k$ is a parameter related to roughness, which can be expressed by the following formula:

$$
k=C \bullet \frac{1}{D \bullet J R C},
$$

where $C$ is a constant coefficient related to opening degree; $D$ is the opening degree $(\mathrm{mm})$; and JRC is the roughness of the joint surface.

In this study, $\mathrm{d} l_{i} \cos \theta_{i}=\mathrm{d} y$, which is substituted into formula (1) to obtain the following formula:

$$
\mathrm{d} \tau=c_{i} \mathrm{~d} y+\sigma_{n} \tan \left(\varphi_{i}+k\right) .
$$

Therefore, the shear strength of the whole frozen joint surface can be expressed as the integral of the shear strength of each element to the projection area of the joint surface on the XOY plane, that is, 


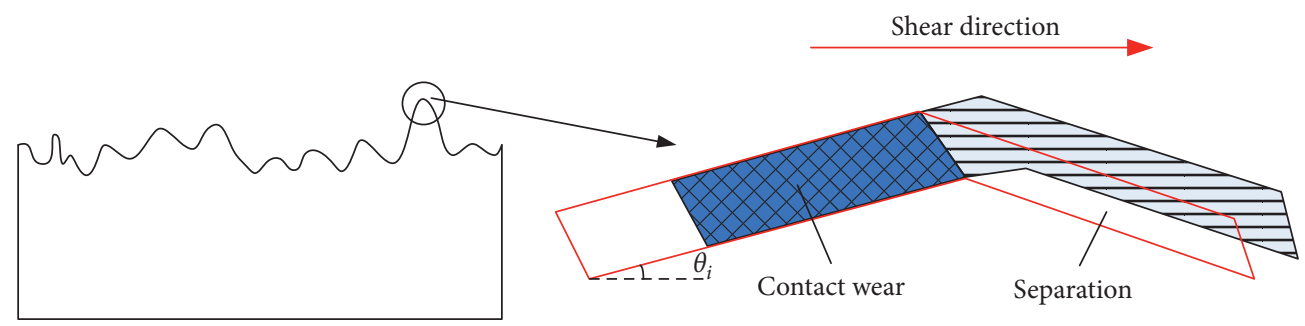

Figure 11: Shear schematic of the joint microelement.

$$
\tau_{p}=\iint_{D_{x y}} \mathrm{~d} \tau=\iint_{D_{x y}} c_{i} \mathrm{~d} y \mathrm{~d} x+\sum_{D_{x y}} \sigma_{n} \tan \left(\varphi_{i}+k\right),
$$

where $D_{x y}$ is the projection area of the joint plane on the $X O Y$ plane.

The damaged specimens are taken out to observe the ice damage between frozen rock joints under various conditions. The results show that when the opening degree of the specimen is 13 or $10 \mathrm{~mm}$ under the low normal stress condition (normal stress is not greater than 1.0 MPa), the failure mode of the specimen is the separation failure between the rock joint surface and the ice layer (as shown in Figure 12(a). At this time, because the opening of the specimens is larger than the fluctuation difference of the joint surface, or the specimens are subjected to a smaller normal stress when the two are approximately equal, the ice compaction is not evident. Hence, the climbing effect hardly occurs during the shear process, and the failure mode is the shear along the weakest surface. Previous studies [21] showed that the bond strength at the ice-rock interface is far less than the shear strength of the ice itself. Therefore, in this case, the failure of specimens overcomes the cohesion and friction between the ice layer and the joint surface, that is, the peak shear strength of specimens consists of the cohesion and friction between the ice layer and the joint surface. However, because the friction coefficient of ice is small, the friction force between ice and joint surface can be neglected compared with the bonding force. At this time, the bond strength between ice layer and joint surface plays a decisive role, that is, the shear strength of specimens is approximately equal to the bond strength between the ice layer and the joint surface. Following the theory of ice adhesion [22], the adhesion strength of ice can be measured by surface energy, and the relationship between ice adhesion and surface energy can be evaluated by the adhesion work $\left(W_{a}\right)$ :

$$
\tau_{p}=W_{a}=\gamma_{s}+\gamma_{l}-\gamma_{s l},
$$

where $\gamma_{s}$ is the surface energy of the solid interface; $\gamma_{1}$ is the surface energy of the liquid interface; and $\gamma_{s l}$ is the interface energy between solid and liquid.

When the opening of specimens is 7 or $10 \mathrm{~mm}$ under high normal stress (normal stress is not less than $1.5 \mathrm{MPa}$ ), the failure mode of specimens is shear failure in ice. The failure of specimens at this time can be divided into two forms. When the opening of the specimen is $7 \mathrm{~mm}$ and the normal stress is greater than $1.5 \mathrm{MPa}$, the effect of ice compaction is evident, and its integrity is destroyed during the compaction process. Therefore, during the shear process, shearing may occur in the ice (as shown in Figure 12(c)). When the opening of the specimens is 7 and $10 \mathrm{~mm}$ and the normal stress is not more than $1.0 \mathrm{MPa}$, the normal displacement of the ice layer is small, and the compaction effect is not evident. However, because the ice thickness is less than the fluctuation difference of the joint surface at this time, the biting effect is strong, and the ice layer and the joint surface do not separate under the climbing effect. The failure mode at this time is shear failure within the ice layer (as shown in Figure 12(b)). In this case, the failure of the specimens overcomes the cohesion in the ice layer and the occlusion force on the joint surface when climbing the slope. At this time, the climbing effect occurs on the shear-oriented joint surface, and shear failure occurs. The strength of this part of the area is determined by the shear strength. The projection area of all shear-oriented slope areas on the XOY plane is assumed to be $D_{1 x y}$. Separation occurs on the joint surface in the direction of back shear, and the strength of this area is determined by the adhesion strength of ice. Assuming that the projection area of all slope areas along the back shear direction on the $X O Y$ plane is $D_{2 x y}$, the adhesion strength of this part is equal to $W_{1 a}$. The sketch of ice stress at this time is shown in Figure 11.

The cohesion of the rock joint surface is $C_{1}$; the internal friction angle is $\varphi_{1}$; the cohesion of ice is $C_{2}$; and the internal friction angle is $\varphi_{2}$. The shear strength of the microelement facing the shear direction is controlled by the shear strength of the joint surface. Meanwhile, the adhesion strength of part microelements separated by shear is controlled by shear strength of ice. The shear strength of the frozen joint surface can be expressed as follows:

$$
\begin{gathered}
\tau_{p}=\iint_{D_{x y}} \mathrm{~d} \tau=\iint_{D_{x y}} c_{i} \mathrm{~d} y \mathrm{~d} x+\sum_{D_{x y}} \sigma_{n} \tan \left(\varphi_{i}+k\right) \\
=\iint_{D_{1 x y}} f\left(c_{i}\right) \mathrm{d} y \mathrm{~d} x+\sum_{D_{1 x y}} \sigma_{n} \tan \left(f\left(\varphi_{i}\right)+k\right) \\
+\iint_{D_{2 x y}} c_{2} \mathrm{~d} y \mathrm{~d} x+\sum_{D_{2 x y}} \sigma_{n} \tan \left(\varphi_{2}+k\right),
\end{gathered}
$$

where $f\left(C_{i}\right)$ is a function related to $C_{1}$ and $C_{2}$ and $f\left(\varphi_{i}\right)$ is a function related to $\varphi_{2}$ and $\varphi_{2}$.

The shear strength of the separated microelements can be expressed by the adhesion strength between the ice layer and the joint surface. 


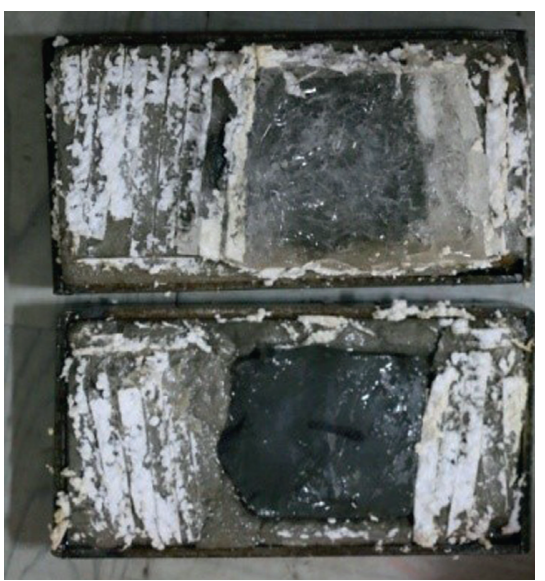

(a)

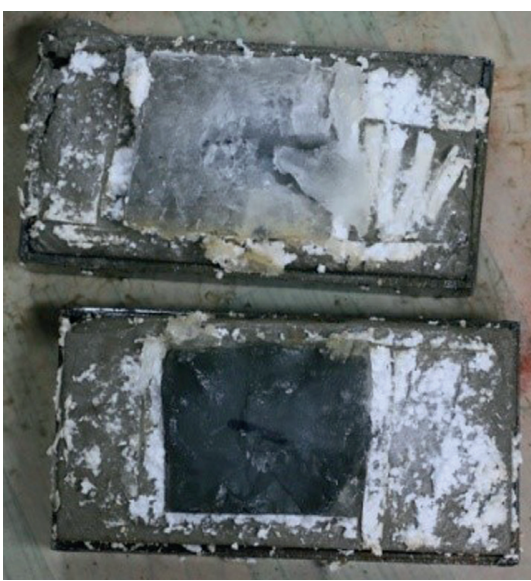

(b)

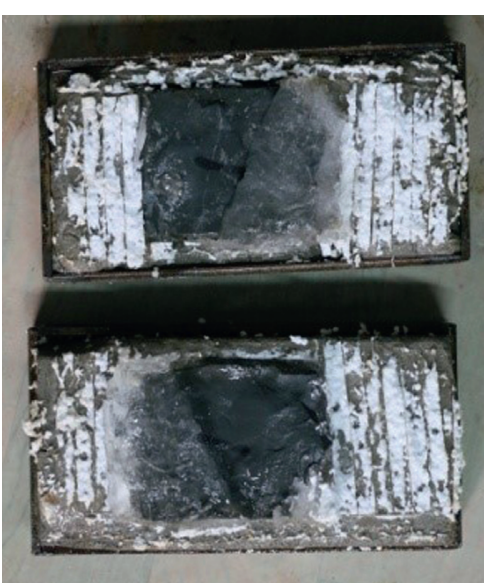

(c)

Figure 12: Photographs of shear failure patterns of frozen joints under different conditions. (a) Disengagement failure of the ice-rock interface. (b) Ice shear damage inside. (c) Shear failure in the ice layer.
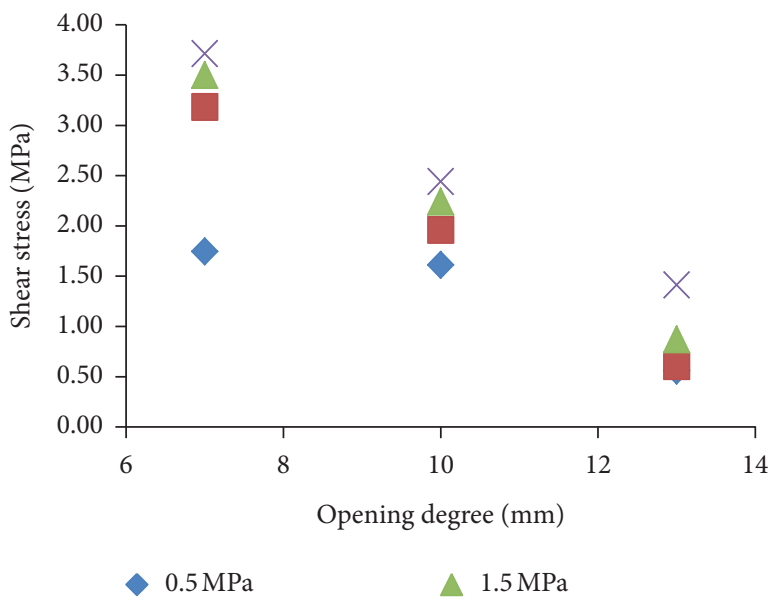

$1.0 \mathrm{MPa}$

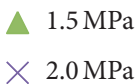

(a)

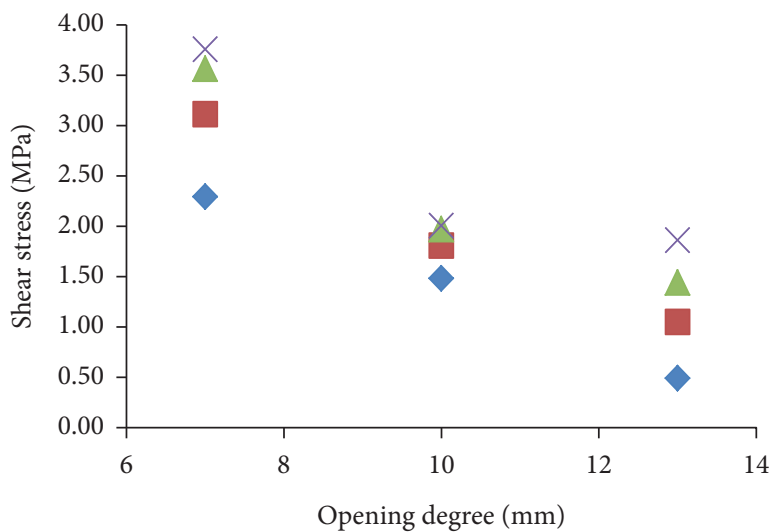

$0.5 \mathrm{MPa}$

$\triangle 1.5 \mathrm{MPa}$

$\times 2.0 \mathrm{MPa}$

(c)

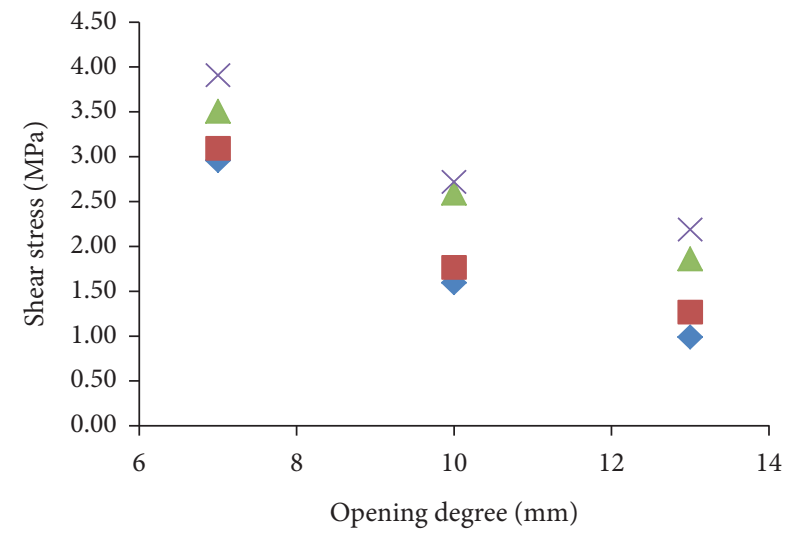

- $0.5 \mathrm{MPa}$

$\triangle 1.5 \mathrm{MPa}$

1.0 MPa

$\times 2.0 \mathrm{MPa}$

(b)

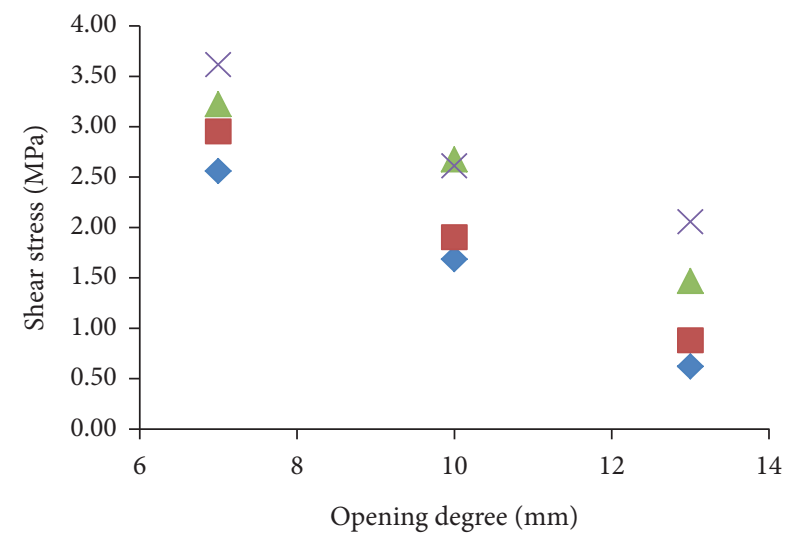

$0.5 \mathrm{MPa}$

$\triangle 1.5 \mathrm{MPa}$

$\times 2.0 \mathrm{MPa}$

(d)

FIGURE 13: Evolution of peak shear strength of frozen joints under different conditions. (a) Specimen 1\#. (b) Specimen 2\#. (c) Specimen 3\#. (d) Specimen $4 \#$. 


$$
\iint_{D_{2 x y}} c_{2} \mathrm{~d} y \mathrm{~d} x+\sum_{D_{2 x y}} \sigma_{n} \tan \left(\varphi_{2}+k\right)=W_{a} .
$$

Therefore,

$$
\tau_{p}=\iint_{D_{1 x y}} f\left(c_{i}\right) \mathrm{d} y \mathrm{~d} x+\sum_{D_{1 x y}} \sigma_{n} \tan \left(f\left(\varphi_{i}\right)+k\right)+W_{a} .
$$

Evidently, the shear strength of frozen joint surfaces in formula (7) consists of the ice adhesion strength of the separated microelements and the climbing strength of the microelements facing the shear direction. $f\left(C_{i}\right)$ and $f\left(\varphi_{i}\right)$ are related to the shear strength of ice and rock joints, respectively. The climbing strength depends on the small values of the occlusion strength of the protruding part of the rock joint surface and the shear strength of the ice layer because the failure of specimens always cuts along the weakest part.

On this basis, when no slope-climbing effect occurs, the shear strength of the frozen joints is composed of the cohesive strength between the ice body and the joint surface. Furthermore, the peak shear strength of frozen joints is small. The peak shear strength increases when the joint surface opening is small, or the normal stress is large. Moreover, climbing effect and occlusion occur in the protruding part of the joint surface during the shear process. It can be seen from the figure that the greater normal stress corresponds to the greater peak shear strength of the joint under the conditions of each opening degree; at the same time, under the same normal stress, the greater opening degree corresponds to the smaller peak shear strength. This is consistent with the determinants of the strength of the frozen joint surface and the failure form under the conditions of different opening degrees mentioned above. Figure 13 shows the variation of peak shear strength of the joint surface under different conditions.

\section{Conclusions}

(1) Under different normal pressures, the shear process of rock frozen joints can be divided into initial deformation, continuously increasing shear stress, ice shearing, and residual shear stages. The shear stressshear displacement curve is concave in the continuously increasing shear stress stage, and the rate of increase in shear stress increases with the increase in normal stress. When the ice shear occurs, the shear stress does not decrease instantaneously. However, it decreases slowly after reaching the peak strength, thereby showing evident flexibility and destructive characteristics.

(2) When the joint opening is close to or greater than its own fluctuation difference, under the action of larger normal stress, damage occurs inside the ice layer, and local failure is prone to occur during shear. The ice layer melts locally by absorbing shear friction heat and soon contacts with the surrounding ice body, thereby resulting in reicing, which leads to rapid rise and fall in shear stress.

(3) When the opening of the joint surface is large, the joint surface itself does not contact during shearing, and the failure is controlled by the adhesion strength between the ice layer and the joint surface. When the joint openness is small, the slope-climbing effect occurs in the shear process. At this time, the failure is controlled by overcoming the occlusion between joint surfaces and the adhesion strength of the ice layer. On the basis of the failure modes of frozen joints under different conditions, it can be divided into three types, namely, the breakage of the ice-rock interface, the shear failure of the ice layer, and the shear failure of the ice layer.

(4) The coordinate system of the joint surface is established, and the microelement is divided. On the basis of the shear strength of the microelement facing shear direction and the adhesion strength of the microelement facing back shear direction during shear detachment, the integral form of the peak shear strength criterion of the joint surface under different opening degrees is derived, and the evolution law of the peak shear strength of frozen joints is obtained.

\section{Data Availability}

The data used to support the findings of this study are available from the first author upon request.

\section{Conflicts of Interest}

The authors declare that they have no conflicts of interest.

\section{Acknowledgments}

This paper was supported by the National Natural Science Foundation of China (no. 41502270) and the National Key Laboratory of Frozen Soil Engineering of Chinese Academy of Sciences (no. SKLFSE201506).

\section{References}

[1] N. Barton, "The shear strength of rock and rock joints," International Journal of Rock Mechanics and Mining Sciences \& Geomechanics Abstracts, vol. 13, no. 9, pp. 255-279, 1976.

[2] G. Grasselli, Shear strength of rock joints based on quantified surface description, Ph.D Thesis, Swiss Federal Institute of Technology, Zürich, Switzerland, 2001.

[3] Y. Liu, J. Liu, and C. Xia, "Research on strength behavior of rock mass containing discontinuous joints by direct shear test under different joint surface morphologies," Rock and Soil Mechanics, vol. 35, no. 5, pp. 1269-1274, 2014.

[4] L. K. -Hui, C. Ping, Z. Ke et al., "Macro and meso characteristics evolution on shear behavior of rock joints," Journal of Central South University, vol. 22, no. 8, pp. 3 087-3 096, 2015.

[5] J.-A. Wang, Y.-X. Wang, Q.-J. Cao et al., "Behavior of microcontacts in rock joints under direct shear creep loading," International Journal of Rock Mechanics \& Mining Sciences, vol. 2, no. 7, pp. 217-229, 2015. 
[6] Z. Tang, Q. Liu, and X. Liu, "Shear behavior of rock joints and comparative study on shear strength criteria with three-dimensional morphology parameters," Chinese Journal of Geotechnical Engineering, vol. 36, no. 5, pp. 873-879, 2014.

[7] L. Yu, X. Xu, M. Qiu et al., "Influnce of freeze-thaw on shear strength properties of saturated silty clay," Rock and Soil Mechanics, vol. 31, no. 8, pp. 2448-2452, 2010.

[8] J. Wang, H. Liu, C. Wu et al., "Influence of freeze-thaw cycles on dynamic characteristics of subgrade soils with different plasticity indices," Chinese Journal of Geotechnical Engineering, vol. 36, no. 4, pp. 633-639, 2014.

[9] A. Zhao, A. Tang, J. Sun et al., "Test on shear strength of cement improved soil under freeze-thaw cycles," Journal of Engineering of Heilongjiang University, vol. 6, no. 1, pp. 28-31, 2015.

[10] S. Ji, A. Wang, and H. Liu, "Analysis of influence factors on the confined compression strength of sea ice in the Bohai Sea," Marine Science Bulletin, vol. 33, no. 4, pp. 371-376, 2014.

[11] Q. Jia, Z. Li, H. Han et al., "Experimental study on shear strength of freshwater ice in a reservoir," Mathematics in Practice and Theory, vol. 45, no. 5, pp. 132-137, 2015.

[12] B. Liu, N. Liu, D. Li et al., "Strength test on frozen cracked red sandstone combined with ice," Journal of China Coal, vol. 41, no. 4, pp. 843-849, 2016.

[13] H. Han, W. Huang, Q. Jia et al., "Study on the unconfined shear strength of large columnar-grained freshwater ice and its influential factors," South-to-North Water Transfers and Water Science \& Technology, vol. 14, no. 6, pp. 39-45, 2016.

[14] T. M. Tharp, "Conditions for crack propagation by frost wedging," Geological Society of America Bulletin, vol. 99, no. 1, p. 94, 1987.

[15] K. Friederike, "Shear strength of ice-filled rock joints," Annals of Glaciology, vol. 31, pp. 463-467, 2000.

[16] M. C. R. Davies, O. Hamza, and C. Harris, "The effect of rise in mean annual temperature on the stability of rock slopes containing ice-filled discontinuities," Permafrost and Periglacial Processes, vol. 12, no. 1, pp. 137-144, 2001.

[17] M. C. R. Davies, O. Hamza, W. Bruce et al., "Laboratory measurement of the shear strength of ice-filled rock joints," Annals of Glaciology, vol. 31, 2000.

[18] F.-A. Martin and P. Rivard, "Effects of freezing and thawing cycles on the shear resistance of concrete lift joints," Canadian Journal of Civil Engineering, vol. 39, pp. 1089-1099, 2012.

[19] Q. Liu, Y. Kang, H. Xing et al., "Critical problems of freezethaw damage in fractured rock and their research status," Rock and Soil Mechanics, vol. 33, no. 4, pp. 971-978, 2012.

[20] C. Xia, J. Huang, C. Han et al., "Methods of frost-heave ratio evaluation and classification of frost-heave susceptibility of tunnel surrounding rocks in cold regions," Chinese Journal of Rock Mechanics and Engineering, vol. 32, no. 9, pp. 1876-1885, 2013.

[21] Z. Tang, C. Xia, and Y. Song, "New peak shear strength criteria for roughness joints," Chinese Journal of Geotechnical Engineering, vol. 35, no. 3, pp. 571-577, 2015.

[22] Y. Ding, S. Tang, and H. Wu, "Study on influence of surface microstructure on ice adhesion strength," Surface Technology, vol. 44, no. 4, pp. 74-78, 2015. 